\title{
PROSPECCÃO TECNOLÓGICA DO CAPIM ELEFANTE E SUA RELEVÂNČA COMO MATÉRIA-PRIMA PARA A PRODUÇÃO ENERGÉTICA
}

\author{
Angela Machado Rocha* \\ Marcelo Santana Silva** \\ Fábio Matos Fernandes*** \\ Luis Cesar M. S. Paulillo***** \\ Ednildo Andrade Torres ${ }^{* * * * *}$
}

RESUMO: Mudanças climáticas e insegurança energética têm contribuído para a demanda crescente por biocombustíveis. $O$ capim elefante, amplamente cultivado no Brasil e utilizado como alimentação animal, está entre as espécies forrageiras de maior eficiência fotossintética para a produção de biomassa com alto teor de lignina, possibilitando o seu uso para fins energéticos como a produção de etanol celulósico. $O$ presente trabalho tem como objetivo realizar uma prospecção tecnológica de artigos e patentes sobre o uso do capim elefante e sua utilização como matéria-prima para a produção energética. Realizou-se uma prospecção tecnológica de publicações relacionadas à biomassa do capim elefante, onde foram extraídos artigos da base de dados Web of Science ${ }^{\circledR}$, da Thomson Reuters e das patentes depositadas na European Patent Office (EPO). Concluiu-se que existe um aumento significativo de publicações de artigos em periódicos e de patentes relacionados ao capim elefante e o Brasil é líder em publicações nas áreas agrícola e veterinária, porém, são poucos os artigos da área de biotecnologia relacionados à produção de biocombustíveis de $2^{\mathrm{a}}$ geração. Foi observado o predomínio dos autores brasileiros, bem como a liderança das instituições brasileiras sobre o tema. Os resultados apresentados podem ser atribuídos ao recente interesse pelo capim elefante para uso energético e fonte de matéria-prima para a produção de etanol de etanol de $2^{\mathrm{a}}$ geração.

PALAVRAS-CHAVE: Bioenergia; Capim Elefante; Geração de Energia; Indicadores de Produção Científica; Prospecção Tecnológica.

Doutora em Energia e Ambiente (UFBA); Docente da Universidade Federal da Bahia (UFBA) e Docente Permanente do Mestrado em Propriedade Intelectual e Transferência de Tecnologia para Inovação (PROFNIT/ Polo UFBA), Brasil.

** Doutor em Energia e Ambiente (UFBA); Docente do Instituto Federal da Bahia - IFBA, Campus Santo Amaro e Docente Permanente do Mestrado em Propriedade Intelectual e Transferência de Tecnologia para Inovação (PROFNIT / Polo IFBA), Brasil; E-mail: profmarceloifba@gmail.com

${ }^{* * *}$ Doutorando em Engenharia Industrial (UFBA); Docente da Universidade Estadual da Bahia (UNEB), Brasil.

**** Doutor em Ciências (USP); Docente da Faculdade de Tecnologia e Ciências (FTC) e Docente Permanente do Mestrado Profissional em Bioenergia (FTC), Brasil

***** Doutor em Engenharia Mecânica (UNICAMP); Docente da Universidade Federal da Bahia (UFBA) e Docente Permanente do Doutorado em Energia e Ambiente (UFBA), Brasil. 


\section{TECHNOLOGICAL PROSPECTS OF ELEPHANT GRASS AND ITS RELEVANCE AS PRIME MATTER FOR ENERGY PRODUCTION}

ABSTRACT: Climate changes and energy uncertainties have contributed towards a growing demand for biofuels. Elephant grass, greatly cultivated in Brazil and used as animal fodder, is one of the forager species characterized by high photosynthesis efficiency for the production of biomass with high lignin rates and thus for the production of energy such as cellulose ethanol. Current analysis comprises a technological prospection of articles and patents on the use of elephant grass and its use as prime matter for energy production. A technological prospection was undertaken in published articles on elephant grass-based biomass, derived from databases Web of Science ${ }^{\circledR}$ and Thomson Reuters and from patents at the European Patent Office (EPO). Results demonstrate a significant increase of articles published in journals and of patents related to elephant grass. In fact, Brazil ranks high in publications on agriculture and veterinary science, even though articles on biotechnology related to second generation biofuel production are few. Brazilian authors and Brazilian institutions predominate on the theme. The above results may be attributed to recent interests in elephant grass for energy and source of prime matter for the production of second generation ethanol.

KEY WORDS: Bioenergy; Elephant grass; Energy production; Indexes of Scientific Production; Technological prospection.

\section{INTRODUÇÃO}

Mudanças climáticas, questões de ordem econômica e segurança energética têm impulsionado a busca por fontes renováveis de energia, principalmente pelos biocombustíveis. O Brasil possui experiência e tradição no uso da biomassa como energia, que remonta às pesquisas iniciadas pelo Instituto Nacional de Tecnologia (INT) na década de 1920 (INT, 2005). Em 1975, foi lançado o Programa Nacional do Álcool Combustível (Proálcool), que posicionou o país como maior produtor mundial de etanol de cana-de-açúcar e, na primeira metade da década de 2000, foi implementado pelo governo federal o Programa Nacional de Produção de Biodiesel (PNPB), que introduziu o biodiesel na matriz energética. Hoje, o Brasil é um dos líderes de produção e consumo de biodiesel (BRASIL, 2012). 
Segundo WEC (2010) sobre cenários futuros de uso de fontes renováveis, a previsão é de que em 2020, os novos combustíveis possam representar um percentual de 3 a 12\% do total de suprimento da energia primária. Pelas projeções, a biomassa tradicional - lenha e outros resíduos naturais - será reduzida para aproximadamente $20 \%$ da demanda de energia total nos países em desenvolvimento. A biomassa moderna, que faz uso de tecnologias avançadas para a produção de eletricidade e biocombustíveis poderá substituir, aos poucos, a biomassa tradicional nas áreas rurais em torno do mundo.

Dentro deste contexto, as gramíneas, amplamente utilizadas como forrageiras, podem exercer papel adicional como culturas energéticas, pois apresentam maior conteúdo de lignina e celulose em relação às culturas anuais. A maioria dos estudos com gramíneas perenes como fonte energética tem foco na sua utilização como combustível sólido, para produção de pellets e eletricidade. No entanto, estudos piloto e de laboratório têm considerado essa biomassa para a produção de etanol (LEWANDOWSKI et al., 2003).

Entre as gramíneas com grande potencial para a produção de etanol está o capim elefante (Pennisetum purpureum), também conhecido por capim napiê. De acordo com Brunken (1977), o capim elefante tem como centro de origem a África Tropical, sendo os territórios da Guiné, Moçambique, Zimbábue e do Quênia as principais áreas de diversidade genética da espécie.

Esta gramínea foi introduzida no Brasil na década de 1920 por possuir boa adaptabilidade às condições de clima e solo. Atualmente, é cultivado em todo o país em sistema de capineira, sendo posteriormente fornecido ao gado em período de escassez de pasto (SHIMOYA et al., 2002; EMBRAPA, 2015).

Devido ao seu rápido crescimento e produtividade, sua biomassa apresenta grande potencial para uso não apenas na alimentação de animais, mas também como fonte de energia alternativa pelo seu teor de fibras, lignina e alta relação carbononitrogênio (ANDRADE et al., 2005).

Por apresentar um sistema radicular desenvolvido, o capim elefante pode contribuir de forma eficiente para aumentar o conteúdo de matéria orgânica ou o sequestro de carbono no solo. Esta gramínea também apresenta baixa necessidade de adubação devido à sua capacidade de reciclagem de nutrientes pelo rizoma 
e poucas pragas ameaçam esta cultura, o que contribui para redução do uso de defensivos agrícolas (MORAIS et al., 2009).

O capim elefante está entre as espécies de forrageiras com maior eficiência fotossintética e possui número básico cromossômico igual a 7 , tendo evoluído como alotetraplóide $(2 \mathrm{n}=4 \mathrm{x}=28)$, com comportamento diplóide normal (BRUNKEN, 1977; SILVA et al., 2008).

Com relação à sua alta eficiência fotossintética, a grande acumulação de matéria seca ( 40 t/ha/ano em média) e o ciclo produtivo de 2 a 4 cortes ao ano, fez com que a Embrapa Agrobiologia, após uma década de pesquisas, intitulasse o capim elefante como campeão de produtividade de biomassa no Brasil (OSAVA, 2007).

Ainda de acordo com Osava (2007), o capim elefante é mais eficiente do que outras culturas. Com o mesmo volume de biomassa vegetal, obtêm-se rendimento 84\% superior à cana-de-açúcar e $37 \%$ ao eucalipto para a geração de eletricidade.

Segundo Salgado (2010), é demonstrado que a eficiência energética do capim elefante com relação à produtividade média do capim elefante é de 40 toneladas de matéria seca por hectare (Figura 1), bem superior ao rendimento médio da cana-deaçúcar que é de 20 ton. de matéria seca/ha e o eucalipto produzindo em torno de 15 toneladas na mesma área.

Mas para tornar a comparação mais palpável, tente imaginar uma medida de calor gerada por essa biomassa. Assim, aquele mesmo hectare plantado de capim-elefante é capaz de aquecer a $40{ }^{\circ} \mathrm{C}$ água suficiente para que uma pessoa tome cinco banhos com oito minutos de duração cada um. Com a cana, o número cai para três banhos, enquanto que o eucalipto daria para apenas duas chuveiradas de oito minutos.

O capim-elefante também está à frente no tempo de espera até a colheita. Após seis meses do plantio, ele já está pronto para ser colhido e a retirada da planta pode ser feita até duas vezes por ano. A cana-de -açúcar precisa de pelo menos um ano para a primeira colheita, enquanto que o eucalipto demora cerca de sete anos para alcançar um bom tamanho para o corte. Mas a competição fica empatada quando se trata de "quem é mais verde". As três plantas são excelentes fontes de energia renovável, a diferença está no fato de o capim-elefante ser o mais produtivo. (SALGADO, 2010). 


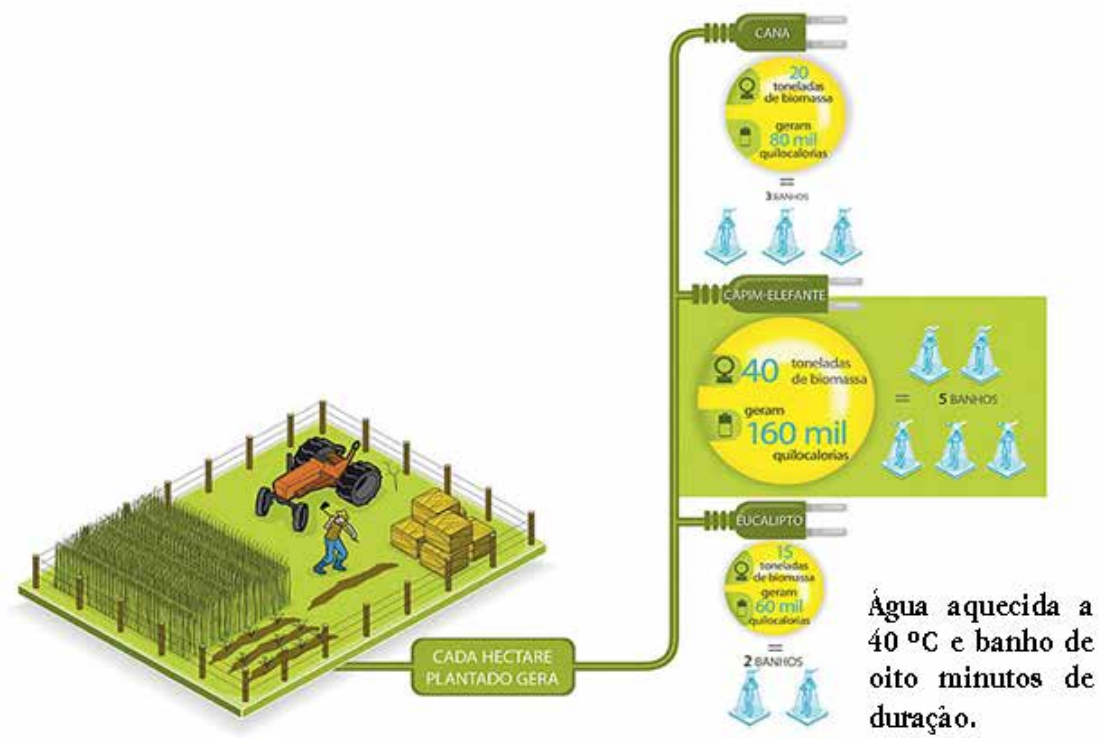

Figura 1. Exemplo da eficiência energética do capim elefante Fonte: Salgado (2010).

A usina Sykuê Bioenergia, localizada no município de São Desidério=(BA), foi a pioneira na geração de energia elétrica a partir de capim elefante ao produzir 30 megawatts, suficientes para iluminar durante um ano uma cidade de 200 mil habitantes (VARGAS, 2010). No Estado de Goiás, algumas indústrias de cerâmica vermelha fizeram experiências ao substituir a lenha utilizada nos fornos por esta gramínea (EMBRAPA, 2015).

Para Capimelefante.org (2014), o capim elefante tem potencial de suprir $10 \%$ da oferta interna de energia no país. Para estimar este valor, obteve a relação de conversão de toneladas de biomassa em MWh que é informada pelos fabricantes dos equipamentos, em função da experiência acumulada, umidade da biomassa e de outros dados disponíveis. Na sequência, avaliou dados de um fabricante de equipamentos de origem europeia, mais familiarizado com as biomassas brasileiras. Para 15\% de umidade, a relação é de 0,98 toneladas/MWh. Finalmente, pode estimar a área necessária ao plantio de capim elefante para suprir $10 \%$ da oferta interna de energia do país, conforme o Quadro 1 abaixo: 
Quadro 1. Área necessária para suprir 10\% de energia interna do país com o capim elefante

\begin{tabular}{|c|c|}
\hline Oferta interna de energia & 270,8 Mtep $^{(1)}$ \\
\hline Energia renovável & 122,8 Mtep $^{(1)}$ \\
\hline $10 \%$ da oferta de energia renovável & 12,3 Mtep \\
\hline $1 \mathrm{MWh}$ & 0,22 tep $^{(1)}$ \\
\hline $\begin{array}{l}1 \text { ha capim - } 15 \% \mathrm{TU}^{4} \text { com produtividade de } \\
40 \text { t.ms/ha/a produz }\end{array}$ & $40,8 \mathrm{MWh}^{(2)}$ \\
\hline $\begin{array}{l}\text { Área necessária de capim elefante } \\
\left(\mathrm{TU}^{4}=15 \%\right)\end{array}$ & $\begin{array}{c}1.368 .092 \text { ha } \\
\text { (ou 15,1\% da área de cana do Brasil) }{ }^{(3)}\end{array}$ \\
\hline
\end{tabular}

(1) BEN 2011 - ano base 2010 (MME);

(2) Fabricante de equipamentos de origem europeia;

(3) IBGE - 2010 (9.080.769 ha colhidos na safra 2010);

(4) Umidade Total.

Fonte: CAPIM ELEFANTE.ORG (2014).

Diante deste estudo, pode-se inferir que 1,37 Mha, correspondente a aproximadamente $15,1 \%$ da área plantada com cana-de-açúcar no Brasil, se plantada com capim elefante, é suficiente para poder suprir $10 \%$ da oferta interna de energia no Brasil.

Apesar das vantagens apresentadas, existem desafios a serem solucionados para aumentar a viabilidade técnica e econômica do capim elefante para uso energético. Como, por exemplo, seu elevado teor de água e necessidade de compactação para viabilizar o transporte e armazenamento. Os custos logísticos são elevados pelo percentual de umidade, e os altos teores de $\mathrm{K}$ e cinzas podem causar problemas para a produção de carvão na siderurgia (MAZZARELA, 2007).

Algumas pesquisas estão buscando também viabilizar o uso do campim elefante como matéria-prima para a produção de etanol de $2^{\mathrm{a}}$ geração, com a vantagem que seu plantio causaria menores problemas ao solo, como acontece com o cultivo da cana-de-açúcar (SCHOLL et al., 2015; JONKER et al., 2015; FONTOURA et al., 2015).

No Brasil, o etanol é obtido a partir do processo de fermentação alcoólica da sacarose presente no caldo da cana-de-açúcar. É também conhecido como "etanol de primeira geração". Os processos que utilizam a matéria-prima lignocelulósica 
resultam no chamado "etanol de segunda geração". Há numerosas pesquisas para o desenvolvimento e produção em larga escala de etanol a partir de lignocelulose, biopolímero mais abundante da terra e que compreende cerca de $50 \%$ da biomassa no mundo (CLAASSEN et al., 1999).

A motivação para a produção de etanol de $2^{\mathrm{a}}$ geraçãoé decorrente da crescente demanda por esse biocombustível. Isso se deve ao crescimento dos mercados já consolidados e de leis governamentais que impulsionam a produção mundial a patamares que só poderão ser atendidos através de mudanças significativas no processo, incluindo novas matérias-primas. Tais tecnologias permitirão a utilização de biomassas de origens diversas, a exemplo do capim elefante, para a produção de etanol de segunda geração e outros biocombustíveis, podendo inclusive ser integradas ao processo convencional de produção de etanol de cana-de-açúcar (AMBROSIO, 2011).

Diante do exposto, o presente trabalho tem como objetivo realizar uma prospecção tecnológica de artigos e patentes sobre o uso do capim elefante e sua relevância como matéria-prima para a produção energética.

\subsection{DESCRIÇÃO DA TECNOLOGIA}

O processamento e transformação do capim elefante em bioeletricidade são relativamente simples. Após a colheita, a planta é desidratada via Sistema de Membranas e posteriormente as folhas são trituradas. Em seguida, a biomassa é depositada em caldeiras, onde é queimada e convertida em energia elétrica. Caso necessite ser armazenado antes da combustão direta, ou precise ser transportado, é transformado em pellets ou briquetes (HENRIQUES, 2009).

Para conversão em etanol, o processo é mais elaborado. O complexo lignocelulósico é constituído por uma matriz de celulose e lignina ligada por cadeias de hemicelulose. Durante o pré-tratamento, esta matriz deve ser quebrada, a fim de reduzir o grau de cristalinidade da celulose. Para a fermentação de materiais lenhocelulósicos, a celulose deve ser degradada em glicose (sacarificação), utilizando ácidos (processo químico) ou enzimas (processo biológico). No primeiro caso, ácidos concentrados ou diluídos podem ser utilizados. Atualmente, a hidrólise 
da celulose é realizada empregando-se enzimas microbianas celulolíticas, por ter demonstrado melhores resultados em razão de não haver formação de componentes de degradação da glicose, embora o processo seja mais lento (CHAGAS, 2012).

A biomassa seca do capim elefante pode gerar 25 unidades de energia para cada unidade de origem fóssil consumida em sua produção. A cana-de-açúcar, que até pouco tempo era considerada líder em eficiência energética, é capaz de alcançar somente nove unidades por cada uma consumida (OSAVA, 2007). O balanço energético entre capim elefante e etanol apresentado por Silva e Rocha (2010) destaca o rendimento final produzido por ambos (Tabela 1).

Tabela 1. Balanço energético entre capim elefante e etanol

\begin{tabular}{lcc}
\hline & Capim elefante & Etanol \\
\hline Energia na produção agro & $0,791-0,668$ & $48.208-45.861$ \\
\hline Energia na peletização & $0,480-0,480$ & $11.800-9.510$ \\
\hline Energia gasta total & $1,271-1,148$ & $60.008-55.371$ \\
\hline Energia produzida & $18,500-18,500$ & $499.400-565.700$ \\
\hline Balanço Energético & $14,6: 1-16,1: 1$ & $8,3: 1-10,2: 1$ \\
\hline
\end{tabular}

Fonte: Silva e Rocha (2010).

\subsection{CONCEITOS BÁSICOS DE PESQUISA E DESENVOLVIMENTO (P\&D)}

Em paralelo aos conceitos técnicos apresentados sobre o capim elefante, faz-se necessário abordar outros conteúdos relevantes, em vista a uma melhor compreensão acerca da fundamentação teórica do presente estudo.

Com o objetivo de lastrear a metodologia adotada são apresentados, de maneira resumida, os conceitos: Inovação; Ciência e Tecnologia (C\&T); Pesquisa e Desenvolvimento (P\&D); e Patente. Também são apresentadas na seção seguinte questões relacionadas à prospecção tecnológica e Tech Mining.

\subsection{INOVAÇÃO}

$\mathrm{Na}$ atual "Economia do Conhecimento", constata-se que o desenvolvimento econômico não resulta apenas do incremento das atividades econômicas e 
estruturais, mas principalmente da capacidade de conferir valor à produção através da informação e conhecimento, incorporando inovações a produtos e serviços que impactam na redução de custos ou em conquista de novos mercados (TIGRE, 2006).

Para Schumpeter (1982) a inovação tem origem em um impulso que é interno ao sistema capitalista. É o que se denomina "Destruição Criativa". Quando se inicia o declínio de um produto ou processo, outro inicia seu ciclo de inovação. Assim, o crescimento do ciclo do novo produto desacelera o ciclo do produto anterior. Considera o autor as inovações radicais como as que provocam grandes mudanças, enquanto que as inovações incrementais são promotoras contínuas do processo de mudança. Em relação à originalidade, entende que as inovações podem ser: novas para o mercado, novas para o mundo, e inovações capazes de provocar rupturas.

\subsection{CIÊNCIA E TECNOLOGIA (C\&T)}

O termo Ciência é entendido como o conjunto organizado dos conhecimentos relativos ao universo, envolvendo seus fenômenos naturais, ambientais e comportamentais. Também pode ser entendida como processo de investigação ou estudo da natureza, direcionado à descoberta das verdades sobre o universo. Já a Tecnologia é definida como o conjunto organizado de todos os conhecimentos científicos, empíricos ou intuitivos empregados na produção e comercialização de bens e serviços.

A forte ligação entre a Ciência e a Tecnologia fez com que surgisse o binômio Ciência e Tecnologia, designado pela sigla C\&T. Apesar de associados, Ciência e Tecnologia possuem naturezas distintas. Enquanto o conhecimento científico é considerado um bem público, uma vez que sua legitimação e aceitação implicam em ampla divulgação sem fronteiras e acesso irrestrito, a Tecnologia é fator de produção e comporta-se como mercadoria (LONGO, 2004).

\subsection{PESQUISA E DESENVOLVIMENTO (P\&D)}

As atividades de Pesquisa, fundamentais na geração da Tecnologia, norteiam-se pela produção de novos conhecimentos e envolvem, frequentemente, 
a experimentação. A Pesquisa Pura, Básica ou Fundamental é realizada com objetivo de aumentar conhecimentos científicos, sem ter, necessariamente, direcionamento específico para a sua aplicação prática. Já a Pesquisa Aplicada dedica-se à busca de novos conhecimentos voltados à busca de soluções sobre problemas previamente definidos. O Desenvolvimento Experimental, também essencial na produção da Tecnologia, é sistemático, embasado em conhecimento existente, originado da pesquisa e/ou da experiência prática (TEIXEIRA, 2011).

\subsection{PATENTE}

A patente, instrumento de proteção mais utilizado na inovação tecnológica, é um direito legal de propriedade sobre uma invenção, garantido pelos escritórios de patentes nacionais, que confere a seus detentores direitos exclusivos, por certo período, para explorar a invenção patenteada e de excluir terceiros, sem sua prévia autorização de comercialização da sua criação. Em contrapartida, o inventor se obriga a revelar todo o conteúdo técnico da matéria protegida pela patente. Extinto o período de proteção da patente concedida, a invenção torna-se de domínio público (QUINTELLA et al., 2006).

De acordo com OCDE (2005), as patentes são os mais apropriados indicadores de inovação, podendo medir os resultados de Pesquisa e Desenvolvimento (P\&D), sua produtividade, estrutura e o desenvolvimento de uma tecnologia/indústria específica.

\subsection{PROSPECÇÃO TECNOLÓGICA E O TECH MINING}

Aferramenta da prospecção tecnológica tem sido decisiva na gestão de Ciência e Tecnologia, assim como na fundamentação nos processos de tomada de decisão referentes à pesquisa, ao desenvolvimento e à inovação (QUINTELLA et al., 2009). É crucial na identificação de oportunidades e necessidades relevantes, entendendo que os desenvolvimentos científicos e tecnológicos resultam de complexa interação entre os atores diversos, das necessidades sociais, oportunidades, restrições econômicas e da consciência ambiental entre outros (COELHO et al., 2010). 
A utilização de métodos potenciais e técnicas de apoio para a tomada de decisões no estabelecimento de Políticas de Ciência, Tecnologia e Inovação têm aumentado no Brasil, resultado de profundas mudanças no país nos aspectos relacionados à globalização da economia e a aceleração das mudanças tecnológicas. Prever o futuro tornou-se um elemento de extrema importância, a fim de aumentar a competitividade das empresas brasileiras e do próprio país, pois permitem vislumbrar avanços, saltos tecnológicos, tendências e descontinuidades, novas perspectivas e mapas de oportunidades (COELHO et al., 2010).

Muitos novos métodos, técnicas e ferramentas atualmente usadas em estudos prospectivos resultaram de avanços na tecnologia e ciência da informação, aliás, com o advento de recursos de informação em formato eletrônico, acessível ao grande público, tornou menores os esforços de coleta e análise da informação (COELHO; SILVA, 2003). Entre eles, destacam-se a cientometria e bibliometria, uma avaliação quantitativa tradicionalmente utilizada pela ciência da informação para mensurar progresso científico e tecnológico, além de identificar redes de cooperação em Ciência e Tecnologia - C\&T (COELHO; SILVA, 2003).

A cientometria é a aplicação de técnicas numéricas analíticas para estudar a ciência da ciência, enquanto que a bibliometria é o tratamento e a análise estatística da mensuração dos resultados através das diferentes publicações científicas refletidas em artigos, livros e em revistas científicas editadas. Como exemplos de indicadores bibliométricos têm-se: o número de patentes registradas por cientistas, o número de artigos científicos publicados, o número de cientistas que publicam artigos científicos, o número de referências bibliográficas citadas nos artigos científicos, o número de citações recebidas por artigo científico. $\mathrm{O}$ uso desses indicadores para estudar atividades de pesquisa de um país parte da premissa que as publicações científicas são um demonstrativo essencial da presença e qualidade destas (SILVA; BIANCHI, 2001).

Um dos maiores desafios nos estudos prospectivos é a grande quantidade de dados. Além disso, é preciso levar em conta a natureza mutável tecnológica e inovação. Porter (2009) afirma que é preciso tratar o texto tal como foi dado, minerar e obter os recursos de inteligência e de informações para responder às perguntas desejadas. Para o autor, o Tech Mining (a Mineração de Dados) procura 
extrair informações úteis a partir de qualquer tipo de dados, enfatizando a análise de dados numéricos. O Tech Mining aproveita fontes de vários tipos de texto.

\section{METODOLOGIA}

Os indicadores bibliométricos são medidas quantitativas da produção bibliográfica de determinado tema ou mesmo de um grupo de pesquisas. Constituem relevantes instrumentos para diretrizes para políticas públicas de Ciência e Tecnologia (C\&T), tais como alocação de recursos e avaliação de programas (JANUZZI, 2002).

A base Web of Science ${ }^{\circledR}$, da Thomson Reuters, é utilizada como padrão mundial para bibliometria, logo, foi utilizada como instrumento de prospecção de artigos para identificar pontos relacionados à biomassa do capim elefante para a geração de energia ou de etanol celulósico.

Com o propósito de verificar o panorama das pesquisas sobre o capim elefante para fins energéticos, a nível mundial e brasileiro, a estratégia utilizada foi buscar artigos que contivessem: Tópico $=($ Pennisetum* purpureum* or elephant* grass $^{*}$ or Napier* grass $\left.^{*}\right)$ OU Título $=$ (Pennisetum* purpureum* ou elefante* grama* ou Napier* grama*); e Tópico $=$ (bioenerg* or eletricity* or pellet* or briquett*) AND Título $=$ (bioenergia* ou eletricidade* ou pelete* ou briquetes*); e Tópico $=\left(\right.$ ethanol* or lignin $*$ or cellul ${ }^{*}$ or alcoohol* or second $*$ generation $*$ or biofuel* or biomass*) AND Título $=($ etanol* ou lignina* ou celulose* ou álcool* ou segunda geração* ou biocombustíveis ou biomassa*).

Vale ressaltar que os artigos prospectados também deveriam possuir as palavras: bioenergia; biomassa; etanol; eletricidade; celulose; lignina; e/ou álcool. Ao todo, foram encontrados 1.401 documentos. No caso das patentes, os dados foram extraídos do banco de dados European Patent Office (EPO) em 28 de setembro de 2013. Foi adotada a mesma estratégia de busca de artigos e foram localizados 50 documentos. Não foi encontrado nenhum registro de patente. Buscou-se então patentes registradas com o termo capim Napier e Pennisetum purpureum, Schum, (nome científico do capim elefante) no título ou no abstract, porém sem sucesso. 


\section{RESULTADOS}

\subsection{RESULTADOS DOS ARTIGOS}

A Figura 2 mostra a evolução anual de artigos referentes ao capim elefante no período de 2002 a 2013. Nota-se que o número de artigos é crescente. Entretanto, apresenta queda entre o período de 2009 a 2011, voltando a crescer em 2012. Essa oscilação pode estar relacionada às restrições financeiras para pesquisas, impostas pela crise econômica mundial que iniciou em 2008 e especificamente no Brasil começou a mostrar sinais de recuperação ao final de 2011 até 2013 e de a partir de 2014, segundo Calixto (2015), o Brasil está à beira de um apagão científico com cortes no valor do custeio da Coordenação de Aperfeiçoamento de Pessoal de Nível Superior (CAPES), da redução dos recursos dos Fundos Setoriais, da crise nos programas estaduais e da paralisação dos editais dos Institutos Nacionais de Ciência e Tecnologia (INCTs).

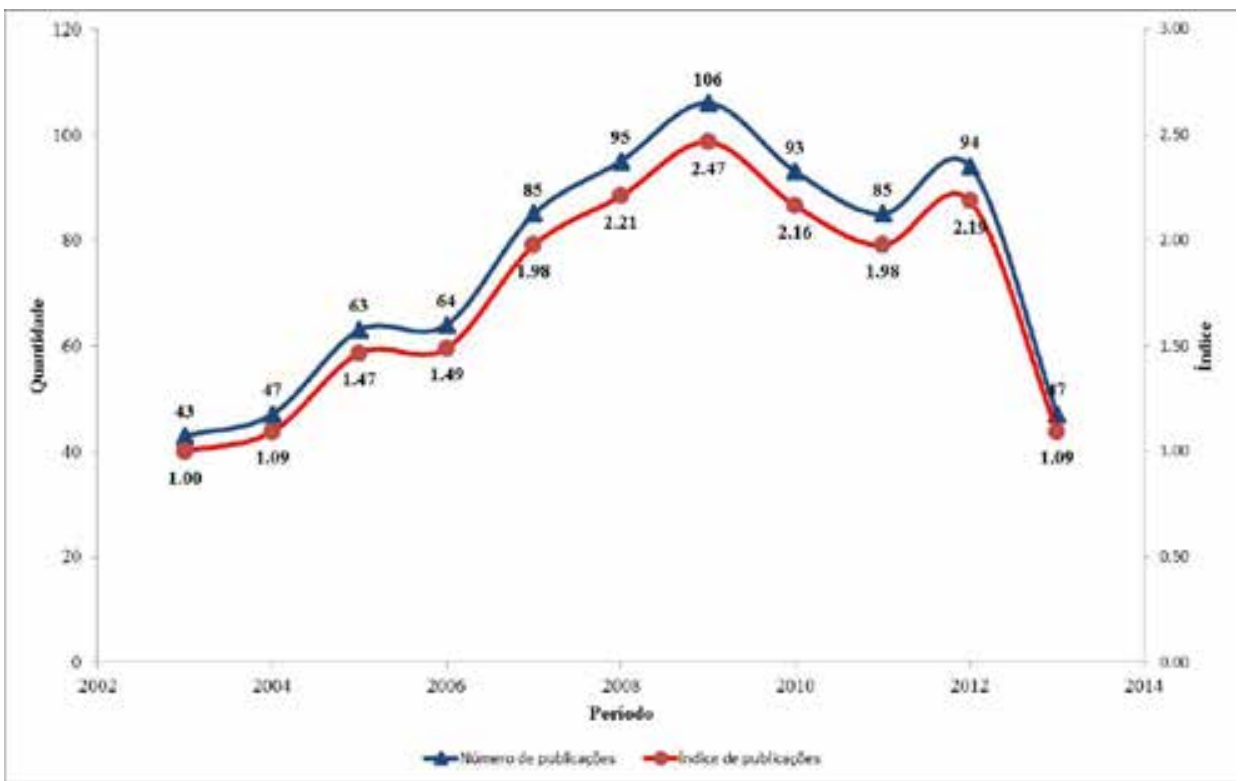

Figura 2. Número de artigos publicados no período 2003-2013

Fonte: Elaborados pelos autores através do Web of Science ${ }^{\circledR}$ 
A Figura 3 apresenta as áreas de conhecimento com maior quantitativo de artigos sobre o capim elefante. Observa-se que a maior parte das pesquisas está concentrada nas áreas agrícola e veterinária, uma vez que as gramíneas perenes são forrageiras largamente usadas na alimentação de animais, especialmente de bovinos. Por possuir um sistema radicular bem desenvolvido, é também objeto de estudo da ecologia ambiental. Entretanto, são poucos os artigos da área de biotecnologia relacionados à produção de biocombustíveis de $2^{\mathrm{a}}$ geração.

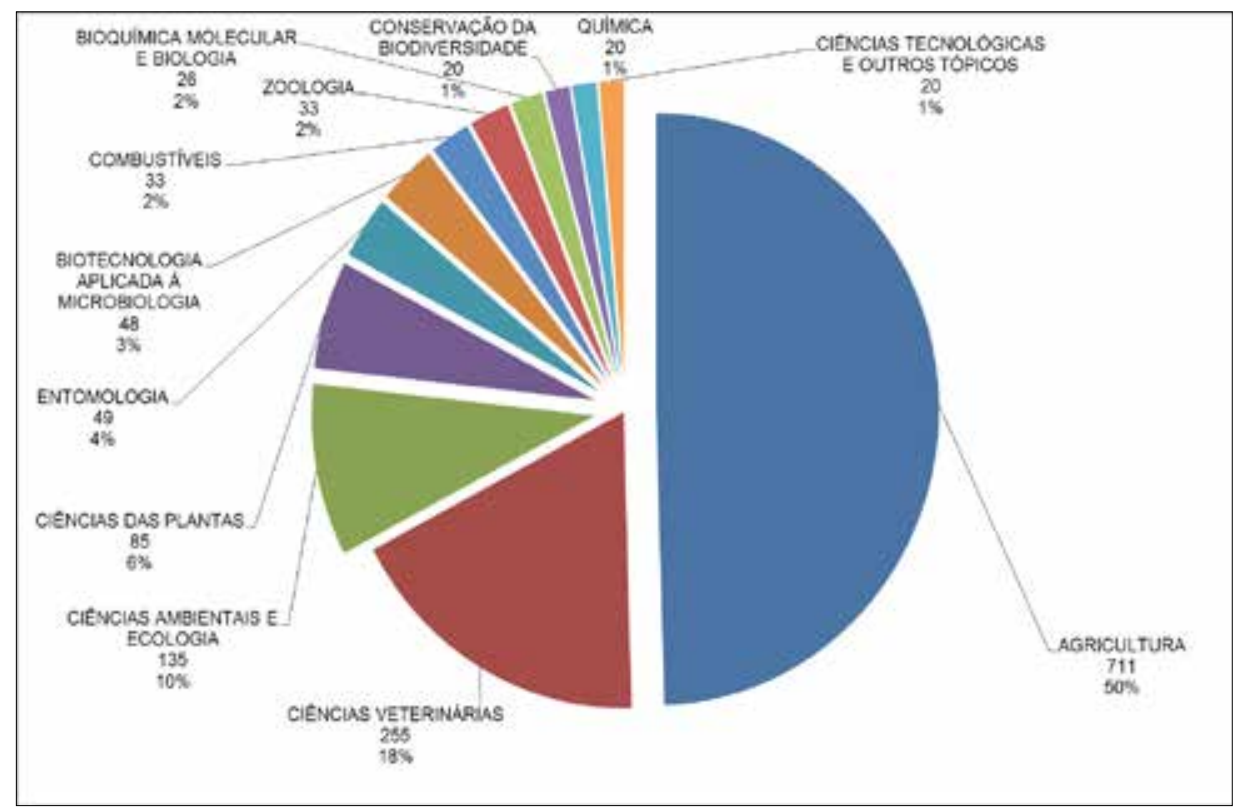

Figura 3. Distribuição das áreas de conhecimentos dos artigos

Fonte: Elaborados pelos autores através do Web of Science ${ }^{\circledR}$

A Figura 4 apresenta os autores com maior número de artigos publicados sobre o capim elefante e seus países de residência. Há hegemonia de autores brasileiros. Como esta gramínea possui origem tropical, é coerente que, pela localização geográfica desses países, existam mais pesquisas sobre o tema. Outro fato que pode estar relacionado ao predomínio dos autores brasileiros é a forte associação da economia dos países em desenvolvimento à atividade primária, em especial a agricultura, onde o capim elefante desempenha papel importante, sendo 
usado como forrageira para alimentação animal.

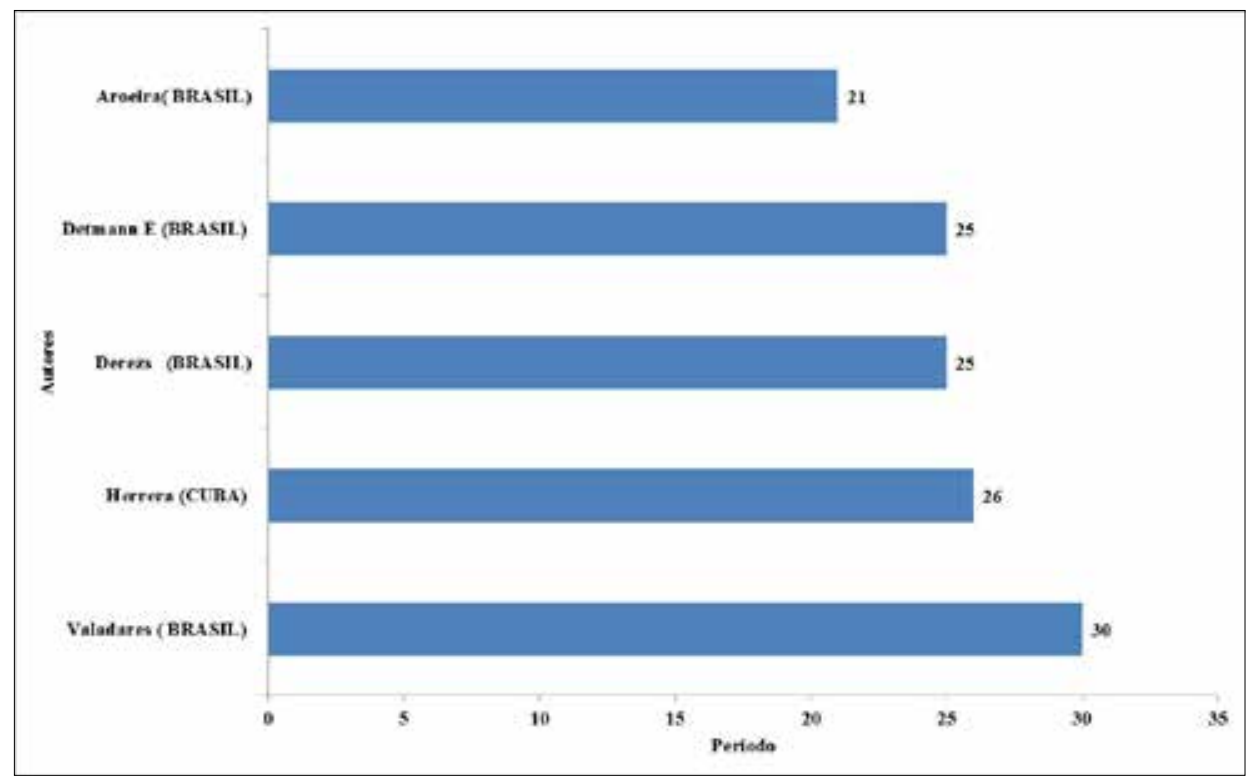

Figura 4. Autores com Maior Número de Artigos

Fonte: Elaborados pelos autores através do Web of Science ${ }^{\circledR}$

A Figura 5 indica a distribuição de artigos publicados de acordo com a nacionalidade dos autores. Observa-se que o Brasil é o líder, seguido dos Estados Unidos. A presença de um país africano como um grande quantitativo de artigos pode ser explicada pelo fato de o capim elefante ser originário da África. 


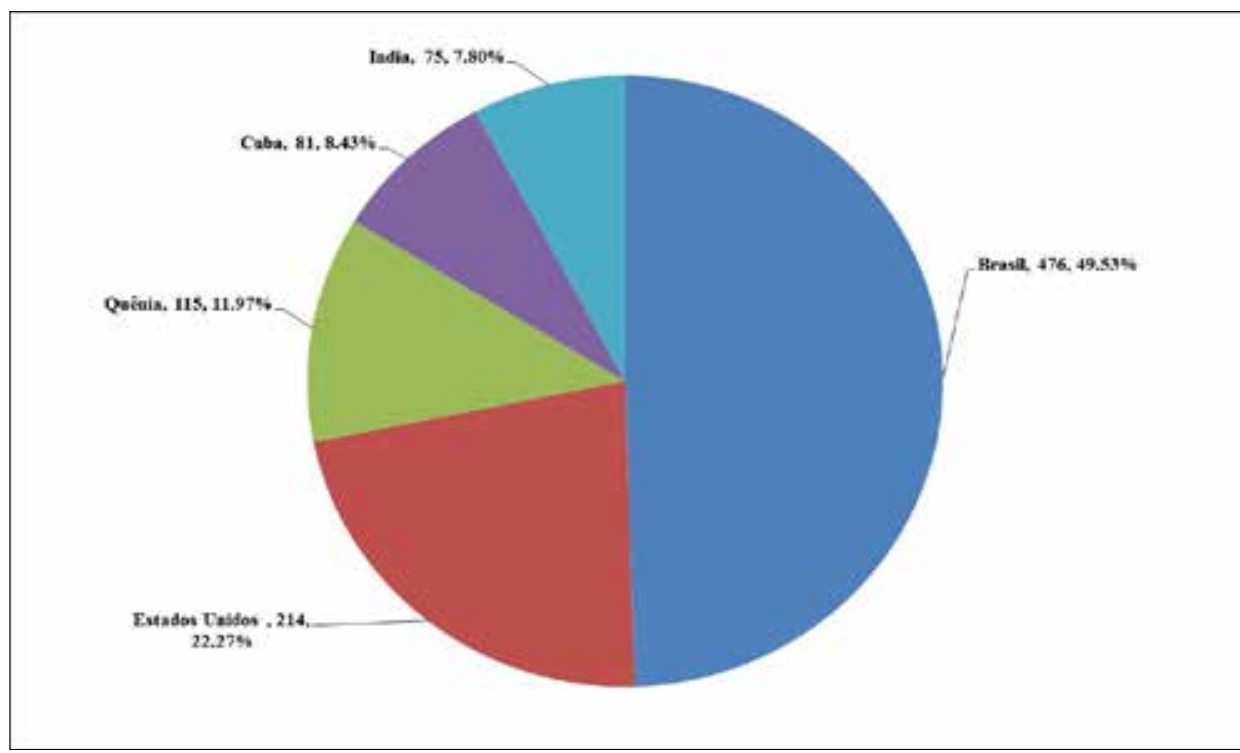

Figura 5. Autores com Maior Número de Artigos

Fonte: Elaborados pelos autores através do Web of Science ${ }^{\circledR}$

A Figura 6 revela as instituições com o maior número de publicações sobre o capim elefante. Observa-se que a maioria das instituições (61,38\%) está localizada no Brasil, com destaque para a Universidade Federal de Viçosa (UFV) e a Empresa Brasileira de Pesquisa Agropecuária (Embrapa), uma das líderes em pesquisa agropecuária. Em seguida vem instituições dos Estados Unidos e Cuba, com 21,96\% e $16,67 \%$, respectivamente). 


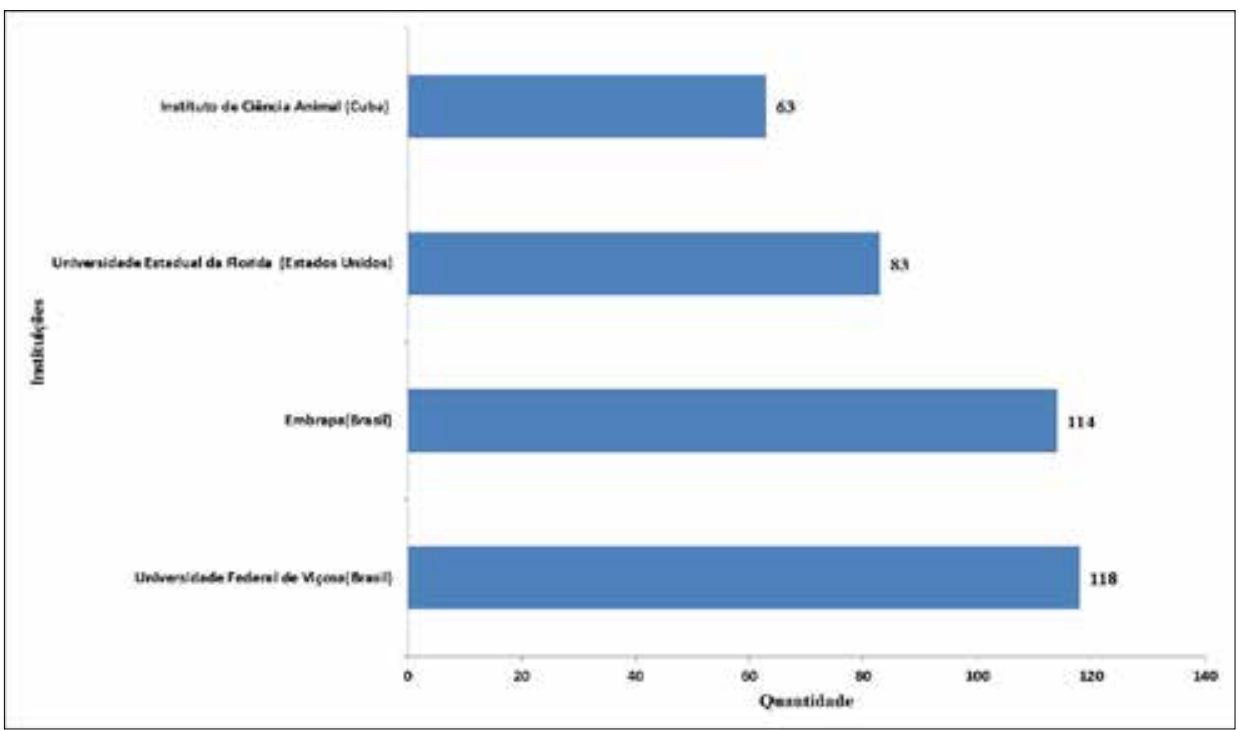

Figura 6. Instituições com Maior Número de Artigos

Fonte: Elaborados pelos autores através do Web of Science ${ }^{\circledR}$

\subsection{RESULTADOS DAS PATENTES}

O primeiro depósito de patente envolvendo o capim elefante data de 1912. Daquele ano até 2013, foram encontrados 50 documentos na prospecção realizada. Cabe ressaltar que o número de depósitos aumentou significativamente entre o período de 2006 a 2013, representando $78 \%$ do número total de patentes depositadas. Este aumento pode ser atribuído ao recente interesse pelo capim elefante para uso com fins energético e como fonte de matéria-prima para a produção de etanol de $2^{\mathrm{a}}$ geração.

Na Figura 7 observa-se a evolução anual dos depósitos dos 50 documentos de patentes sobre o capim elefante encontrados na prospecção do presente estudo. A partir do ano de 2005, existe uma tendência evolutiva significativa e um brusco aumento do número de depósitos (78\% do total). Este aumento pode ser atribuído ao recente interesse pelo capim elefante para uso com fins energético e como fonte de matéria-prima para a produção de etanol de $2^{\mathrm{a}}$ geração. 


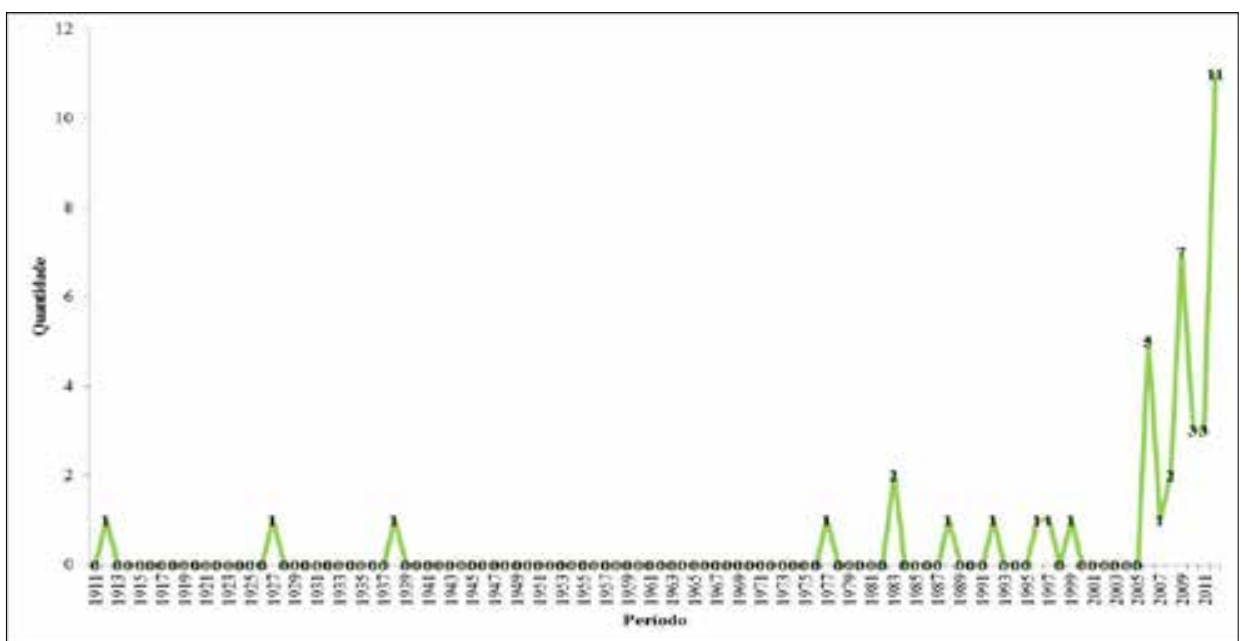

Figura 7. Evolução Anual de Patentes Fonte: EPO.

A Figura 8 apresenta os pesquisadores com maior número de patentes depositadas sobre o capim elefante. Curiosamente, todos possuem o mesmo número de registros (dois). Foram identificados quatro pesquisadores chineses e um de nacionalidade ignorada.

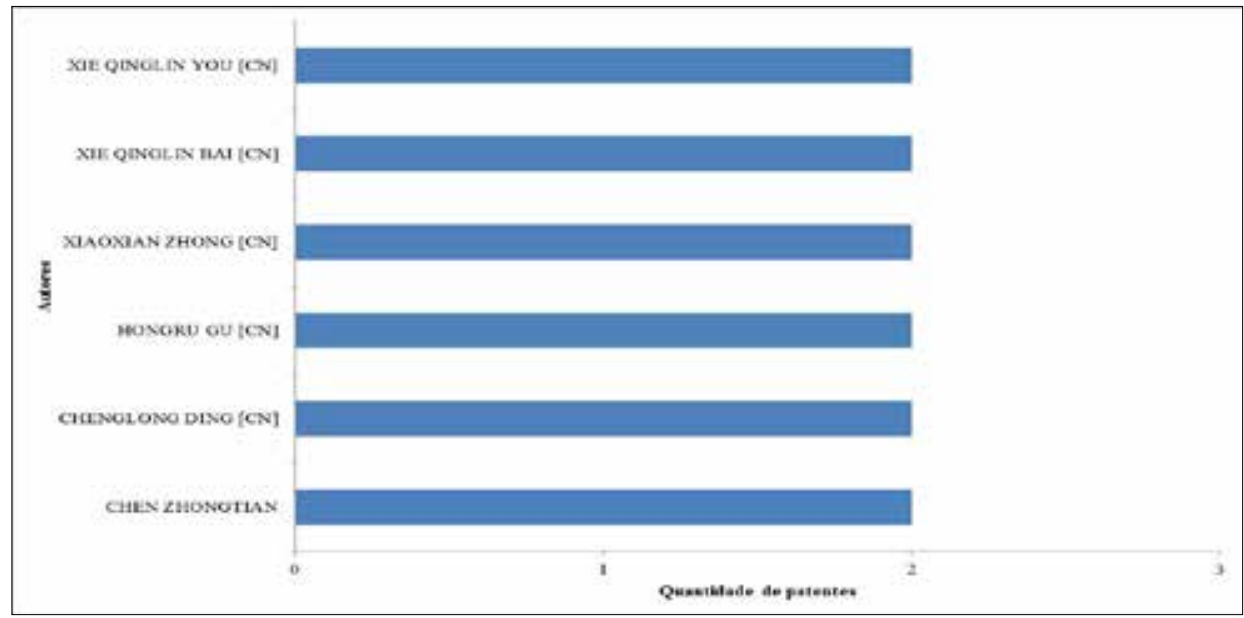

Figura 8. Inventores com mais Patentes

Fonte: EPO. 
É preciso ressaltar que vários documentos sobre as patentes não continham todas as informações, havendo várias lacunas como a nacionalidade dos inventores e dos aplicantes e resumos, entre outros. Embora não tenha sido possível identificar a nacionalidade do inventor Chen Zhongtan, é provável que seja chinês, em razão de seu nome.

A Figura 9 apresenta as instituições com o maior número de depósito de patentes sobre o capim elefante. Vale destacar que duas das três maiores instituições depositantes situam-se na cidade de Guilin, China. Apesar dos nomes semelhantes, Guilin College of Tech e Guilin Polytechnic College, são instituições distintas. A outra depositante é a Academia Sinica, situada em Taiwan. Interessante observar que as instituições acadêmicas são as maiores depositantes de tecnologias com esta gramínea.

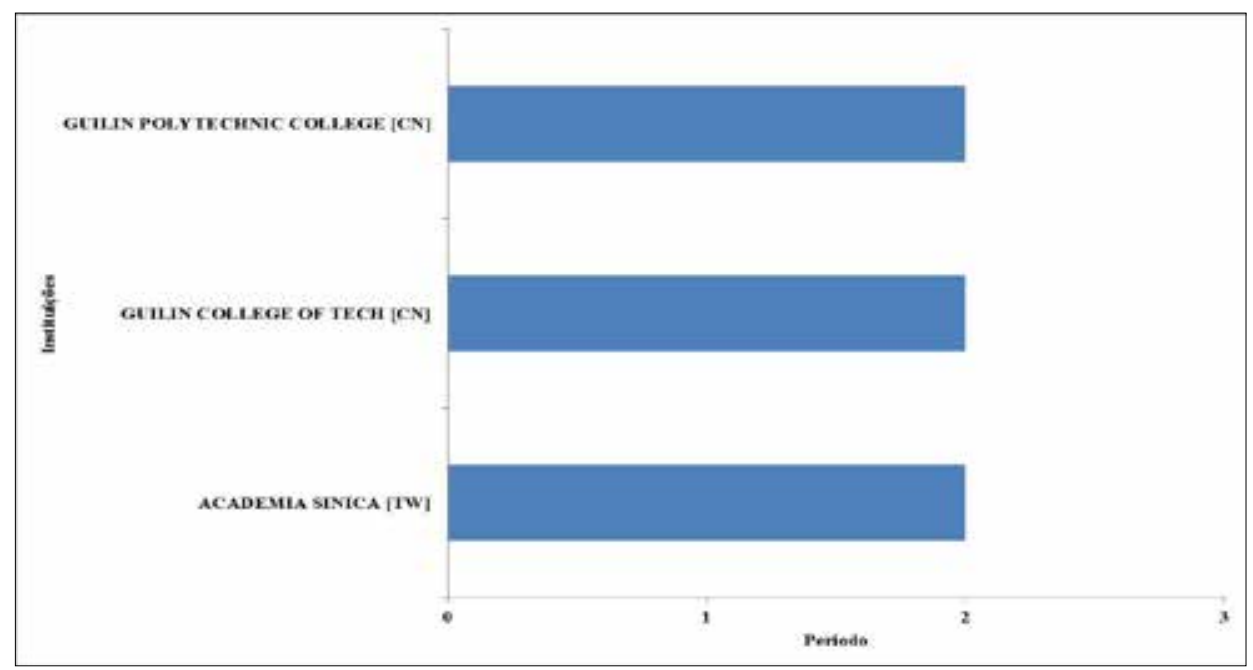

Figura 9. Inventores com mais Patentes

Fonte: EPO.

A Figura 10 revela os Códigos Internacionais mais citados. O código C10L5/44 (Combustíveis sólidos produzidos pela solidificação de combustíveis fluidos com substâncias de origem vegetal) é o líder, o que pode ser justificado pelo fato de capim elefante possuir enorme poder energético. A seguir consta $\mathrm{o}$ código A23K1/14 (Produtos alimentícios para animais a partir de materiais vegetais), o que já era esperado uma vez que primordialmente o capim elefante é usado como 
ração animal. A presença do código A61K36/899 (Preparações medicinais contendo materiais de constituição indeterminada de plantas) pode estar associada a patentes correlatas à tradicional medicina chinesa, que se utiliza largamente de plantas para fins terapêuticos.

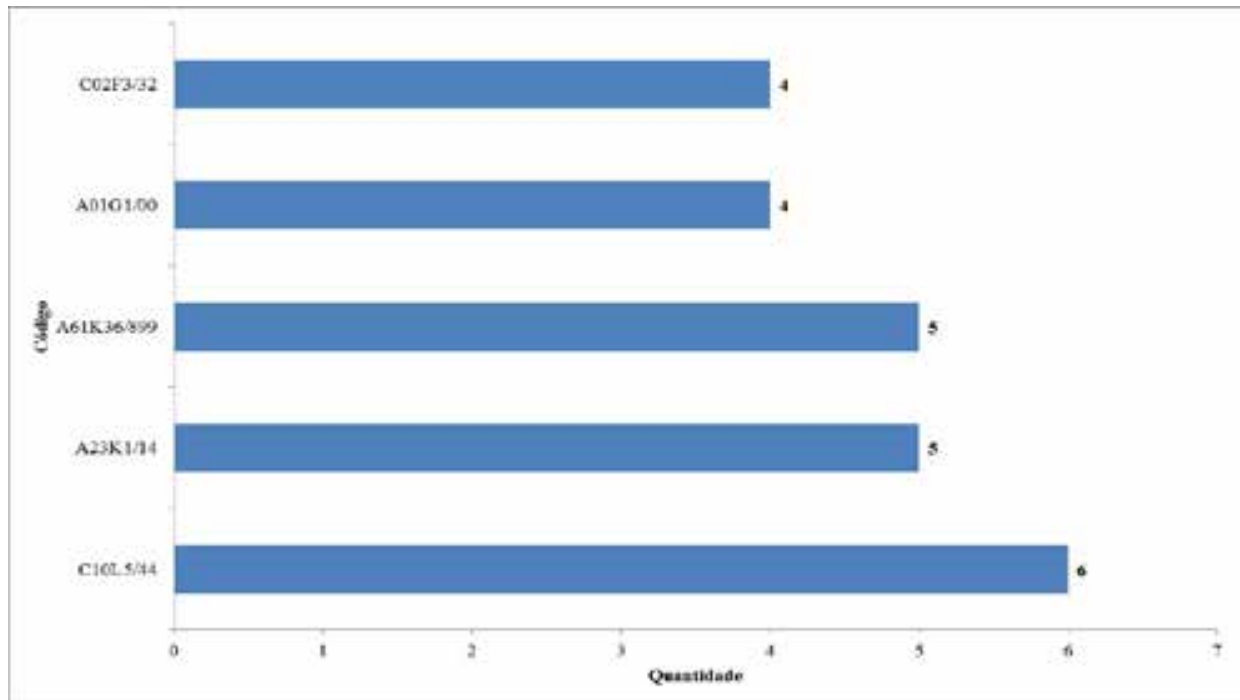

Figura 10. Códigos Internacionais mais Citados nas Patentes do Capim Elefante Fonte: EPO.

O sistema radicular do capim elefante, por ser bem desenvolvido e contribuir de forma eficiente para aumentar o conteúdo de matéria orgânica do solo, pode ter impulsionado pesquisas que resultaram nas patentes que apresentam os códigos A01G1/00 (Horticultura; Cultivo de vegetais). Por fim, o código C02F3/32 (Tratamento biológico de água, águas residuais, caracterizado pelos animais ou plantas) sugere tecnologias que conferem propriedades ao capim elefante como despoluidor de águas e esgotos.

\section{CONSIDERAÇÕES FINAIS}

No Brasil o uso de biomassa para geração de energia é bastante estratégico, visto a alta produtividade das florestas, grande volume de resíduos gerados na 
indústria moveleira, tecnologias modernas de conversão da biomassa em energia elétrica e questões ambientais favoráveis para esta fonte energética.

No aspecto geral foram observados os seguintes resultados sobre o capim elefante: (i) após 2005, houve um aumento significativo em número de depósitos; (ii) a partir de 2002 os números de artigos vêm crescendo satisfatoriamente; (iii) a área agrícola foi a que apresentou maior número de publicação de artigos. Como destaque deste trabalho pode-se afirmar que o Brasil está fortemente associado ao capim elefante, pois foram observados os seguintes destaques: (i) existe predomínio de artigos publicados por autores brasileiros; (ii) o Brasil foi o país que mais publicou artigos sobre esta temática; (iii) as instituições líderes de pesquisa sobre o tema estão localizadas no Brasil.

Pode-se perceber também que a diversificação das biomassas utilizadas para geração de diversos produtos agroenergéticos é essencial para ampliar a oferta de energia. Pelo seu alto rendimento de biomassa e elevado teor de lignina e celulose, o capim elefante é uma interessante alternativa como matéria-prima energética.

Entretanto, os resultados encontrados no trabalho indicam que o desenvolvimento científico sobre o uso do capim elefante para fins energéticos ainda é incipiente, e que há significativos gargalos a serem superados para o desenvolvimento tecnológico e produção de etanol de segunda geração.

Por fim, as políticas públicas e incentivos governamentais destinados à Pesquisa, Desenvolvimento e Inovação (P\&D\&I) do capim elefante para fins energéticos podem promover um salto na evolução tecnológica dos biocombustíveis. Isso representará além de redução de custos de produção, maior sustentabilidade ambiental e desenvolvimento social e econômico.

\section{REFERÊNCIAS}

AMBROSIO, W. A Usina de Cana-de-Açúcar como exemplo de Biorrefinaria. In: VAZ JUNIOR, S. (Ed.). Biorrefinarias: cenários e perspectivas. Brasília: Embrapa Agroenergia, 2011. p 69-78.

ANDRADE, A. C. et al. Análise de crescimento do capim-elefante 'Napier' adubado e irrigado. Disponível em: < http://www.scielo.br/pdf/cagro/v29n2/a20. pdf $>$. Acesso em: 03 set. 2013. 
BRUNKEN, A. V. A systematic study of Pennisetum Sect Pennisetum (graminea). American Journal of Botany, New York, v. 64, n. 2, p. 161-176, 1977.

CALIXTO, B. O Brasil está a beira de uma apagão científico. Época. São Paulo, 06 out. 2015. Disponível em: <http://epoca.globo.com/vida/noticia/2015/10/o-brasilesta-beira-de-um-apagao-cientifico.html> . Acesso em: 18 jan. 2016.

CAPIM ELEFNTE.ORG. Capim elefante: a energia renovável moderna. 2014. Disponível em: <http://www.capimelefante.org/perguntas-frequentes/p25>. Acesso em: 10 mar. 2015.

CHAGAS, A. L. Economia de baixo carbono: avaliação de impactos de restrições e perspectivas tecnológicas. estudos setoriais biocombustíveis. Ribeirão Preto, [S.n.], 2012.

CLAASSEN, P. A. M; van LIER, J. B.; CONTRERAS, L. A. M.; van NIEL, E. W. J.; SIJTSMA, L.; STAMS, A. J. M.; VRIES S. S.; WEUSTHUIS, R. A. Utilisation of biomass for the supply of energy carriers. Appl Microbiol Biotechnol, v. 52, p. 741-755. 1999.

COELHO, G. M. et al. Foresight estratégico: uso da abordagem metodológica no plano de gestão de uma agência de fomento a ciência, tecnologia e inovação. Parcerias Estratégicas-CGEE, Brasília, v. 30, p. 129-159, 2010.

COELHO, G. M.; SILVA, C. H. Prospecção tecnológica em patentes no setor de óleo e gás. In: WORKSHOP BRASILEIRO DE INTELIGÊNCIA COMPETITIVA E GESTÃO DO CONHECIMENTO, 4., 2003, Salvador. Anais... Salvador, 2003.

EMBRAPA. Pesquisa investe em capim como fonte de energia. Disponível em: $<$ https://www.embrapa.br/busca-de-noticias/-/noticia/2422024/pesquisa-investeem-capim-como-fonte-de-energia > . Acesso em: 07 mar. 2015.

FONTOURA, C. F.; BRANDAO, L. E.; GOMES, L. L. Elephant grass biorefineries: towards a cleaner Brazilian energy matrix? Journal of Cleaner Production, v. 96, p. 85-93, 2015. 
HENRIQUES, R. Potencial para geração de energia elétrica no Brasil com resíduos de biomassa através da gaseificação. 2009. Tese (Doutorado em Planejamento Energético) - Universidade Federal do Rio de Janeiro, 2009.

INSTITUTO NACIONAL DE TECNOLOGIA - INT. Instituto Nacional de Tecnologia, desde 1921 gerando Tecnologia para o Brasil. Rio de Janeiro: INT, 2005.

JANNUZZI, P. M. Considerações sobre o uso, mau uso e abuso de indicadores sociais na avaliação de políticas públicas municipais. Revista de Administração Pública, Rio de Janeiro, v. 36, n. 1, p. 51-72, 2002.

JONKER, J. G. G.; VAN DER HILST, F.; JUNGINGER, H. M. et al. Outlook for ethanol production costs in Brazil up to 2030, for different biomass crops and industrial technologies. Applied Energy, v. 147, p. 593-610, 2015.

LEWANDOWSK, et al. The Development and Current Status of Perennial rhizomatous Grasses as Energy Crops in the US and Europe. Biomass and Bioenergy, v. 25, p. 335-361, 2003.

LONGO, W. P. Ciência e tecnologia: alguns aspectos teóricos. 2. ed. rev. e atual. Rio de Janeiro: Escola Superior de Guerra, 2004. Disponível em: < http://www.waldimir. longo.nom.br > . Acesso em: 04 set. 2013.

MAZZARELLA, V. N. G. Capim Elefante com fonte de energia no Brasil: realidade atual e expectativas. Jornada Madeira Energética. Rio de Janeiro, 2007.

MAZZARELLA, V. N. G. O Capim que gera negócios. Disponível em: $<$ http://epocanegocios.globo.com/Revista/Common/0,EMI131148-16368,00O+CAPIM+QUE+GERA+ENERGIA.html > . Acesso em: 07 set. 2013.

MORAIS, R. F. Potencial produtivo e eficiência da fixação biológica de nitrogênio de cinco genótipos de capim elefante (Pennisetum purpureum Schum.), para uso como fonte alternativa de energia. 2008. 73f. Dissertação (Mestrado), Universidade Federal Rural do Rio de Janeiro, Seropédica, 2008.

NOGUEIRA, L. A. H. et al. Dendroenergia: fundamentos e aplicações. 2. ed. Rio de Janeiro: Interciência, 2003. 
OSAVA, M. Capim elefante, novo campeão em biomassa no Brasil. Rio de Janeiro: IPS, 2007. Disponível em: < http//www.biotecnologia.com.Br/bionoticias/noticias. asp?id=3502>. Acesso em: 03 set. 2013.

PORTER, A. L. Tech mining for future-oriented technology analyses. In: GLENN, J. C.; GORDON, T. J. (Org.). Futures Research Methodology. [s.l.]: Rockefeller Foundation, 2009.

QUINTELLA, C.M. et al. Cadeia do biodiesel da bancada à indústria: uma visão geral com prospecção de tarefas e oportunidades para P\&D\&I. Química Nova, São Paulo, v. 32, n. 3, p. 793-808, 2009.

QUINTELLA, C.M. et al. Cartilha da PI - Propriedade Intelectual: O quê? Quem? Por quê? Para quê? Salvador: Ed. da EDUFBA: 2006.

SALGADO, R. O capim que gera energia. Época NEGóCIOS, 2010. Disponível em: $<$ http://epocanegocios.globo.com/Revista/Common/0,,EMI131148-16368-1,00$\mathrm{O}+\mathrm{CAPIM}+\mathrm{QUE}+\mathrm{GERA}+$ ENERGIA.html $>$ Acesso em: 20 mai. 2015.

SCHOLL, A. L. et al. Ethanol production from sugars obtained during enzymatic hydrolysis of elphant grass (Pennisetum purpureum, Schum.) pretreated by steam explosion. Bioresource Technology, v. 192, p. 228-237, 2015.

SCHUMPETER, J. A. The theory of economic development. São Paulo: Abril Cultural, 1982.

SHIMOYA, A. et al. Repetibilidade de características forrageiras do capim-elefante. Scientia Agrícola, v. 59, n. 2, p. 227-234, abr.jun. 2002.

SILVA, E.; ROCHA, C. R. Eucalipto e capim elefante: características e potencial produtivo de biomassa. Revista Agrogeoambiental, abr. 2010, p. 143-152.

SILVA, J. A. da; BIANCHI, M. L. P. Cientometria: a métrica da ciência. Paidéia (Ribeirão Preto), Ribeirão Preto, v. 11, n. 21, p. 5-10, 2001. Disponível em: < http:// www.scielo.br/scielo.php?script $=$ sci_arttext\&pid $=$ S0103-863X2001000200002 $\& \ln$ 
$\mathrm{g}=\mathrm{en} \& \mathrm{nrm}=\mathrm{iso}>$. Acesso em: 20 mar. 2015.

SILVA, M. C. et al. Ensaios preliminares sobre autofecundação e cruzamentos no melhoramento do capim-elefante. Disponível em: < http://www.scielo.br/scielo. php?script $=$ sci_arttext\&pid $=\$ 1516-35982008000300004>$. Acesso em: 26 maio 2015.

TEIXEIRA, F. C. O Desenvolvimento brasileiro e a formação do sistema de ciência e tecnologia. In: A FINEP no século XXI. Rio de Janeiro: Ed. da Finep, 2011.

TIGRE, P. B. Gestão da inovação: a economia da tecnologia no Brasil. Rio de Janeiro: Campus, 2006. 282p.

VARGAS, A. A Força do campimtalismo. Revista Veja, 11 de agosto, 2010, p. 112-114.

WORLD ENERGY COUNCIL - WEC. World Energy Insight 2010. United Kingdom, 2010d. Disponível em: < http://www.worldenergy.org/publications/default.asp>. Acesso em: 05 jun. 2013.

Recebido em: 14 de julbo de 2015 Aceito em: 21 de fevereiro de 2016 